\title{
A Practical Comparative Evaluation of Different Active Harmonic Filter Topologies
}

\author{
P. Salmerón, S. P. Litrán, R.S. Herrera, J. R. Vázquez \\ Departamento de Ingeniería Eléctrica y Térmica \\ Escuela Politécnica Superior, Universidad de Huelva \\ Ctra. de Palos de la Frontera s/n, 21819, Palos de la Frontera, Huelva, Spain \\ Phone: +34-959217585, Fax: +34-959217304 \\ e-mail: patricio@uhu.es; salvador@uhu.es; reyes.sanchez@die.uhu.es; vazquez@uhu.es
}

\begin{abstract}
Along the last years, the practical use of active filters to mitigate harmonics has been extended in electric power systems. Different configurations of series active filters versus shunt active filters have been proposed, among them, hybrid topologies which combine active and passive filters. Nevertheless, there is not any clear accordance about the most suitable configuration for each type of harmonic sources. In this paper, four different topologies of active power filters to eliminate harmonics have been analyzed. An experimental prototype has been implemented to each configuration and have been submitted to different performance tests. With this objective, a test bank has been developed, which includes nonlinear loads kind harmonic current source, ahrmonic voltage source, and other whose behavior is between they both. The analysis of experimental results obtained allows the most suitable active filter power topology to be determined for each type of load.
\end{abstract}

\section{Key words}

Power quality, active filters, hybrid filters, harmonics.

\section{Introduction}

Harmonics exist in electrical networks since the beginning of the electrical engineering. Along the years, different techniques have been applied and different devices have been used to mitigate harmonics, mainly based on passive filters configurations. Nevertheless, at the end of the seventies, equipments constituted by power electronic converters were presented to eliminate harmonics. It was the beginning of a new period corresponding to the called active power filters, APFs. Different topologies and control strategies have been proposed to make practical use of these equipments, [1-3].

An active power filter is a static compensation system based on a power electronic converter using a PWM (Pulse Width Modulation) control technique. The converter allows the suitable voltage or current waveform to be generated according to the proposed compensation target.
The most extended APF in the technical literature and the most used in low voltage system is the shunt active power filter. It supplies to the electrical networks a harmonic current whose amplitude is the same as the load current harmonics and whose phase is in opposite way. The performance of this configuration kind has been analyzed for loads as phase-controlled thyristor rectifier with SCRs (Silicon Controlled Rectifier) and a large inductance in DC side, cycle-converters or regulators constituted by branches composed of two antiparalell SCRs. These nonlinear loads can be considered harmonics current sources (HCS). However, other types of non-linear loads like diode rectifiers with direct smoothing DC capacitors are considered harmonics voltage sources (HVS). Using filters to compensate HVS nonlinear loads does not completely eliminate the load current harmonics, therefore, its use is ineffective in this situation, [1].

With HVS loads, the use of series active filters has been proposed. They constitute a suitable harmonic compensation equipment for this type of load, although it is not commonly used in low voltage networks.

Besides shunt and series active filters, other topologies constituted by a combination of active and passive filters have been proposed. Passive filters are LC branches tuned to main load harmonics frequencies. These configurations are generally known as hybrid filters, [3].

On spite of the high number of papers published about the different compensation systems with APFs, there are not many practical studies that analyze the performances of the most usual configurations to compensate harmonics in low voltage networks.

In this paper, four different filter topologies to eliminate harmonic have been used and compared. They are:

- Shunt active power filter, PAF (Parallel Active Filter), Fig. 1, [4].

- $\quad$ Series active power filter, SAF (Series Active Filter), Fig. 3, [6]. 
- Active filter connected in series with a parallel passive filter, PPAF (Parallel Passive-Active Filter), Fig. 5, [7-9].

- Series active filter and shunt passive filter, SAPPF (Series Active and Parallel Passive Filter), Fig. 7, [1012].

Each topology has been used to compensate harmonics generated by a HVS load, a HCS load and a load that presents an intermediate behavior between both. The compensation target was the elimination of load harmonics for all configurations. Thus, the determination of current harmonics in the source side has been needed in the active filter control design. For this reason, the reference signal calculation has been carried out according to the same control method in all the configurations.

An experimental prototype corresponding to each topology has been designed. They have been used to carry out the comparative analysis. The most significant results obtained from the tests carried out for compensation equipments and each type of load has been presented.

\section{Active Harmonic Filters: Compensation Strategies}

From now on, harmonics filtering characteristics corresponding to the four topologies of APFs used in this paper are introduced. By means of the equivalent singlephase circuits and applying the superposition principle, source current harmonics and PCC voltage harmonics are obtained.

\section{A. Parallel active filter, $P A F$}

Fig. 1 shows the PAF connection to a power system. The parallel active filter is modeled like a controlled current source connected in shunt to the load to supply the compensation current, Fig. 2.

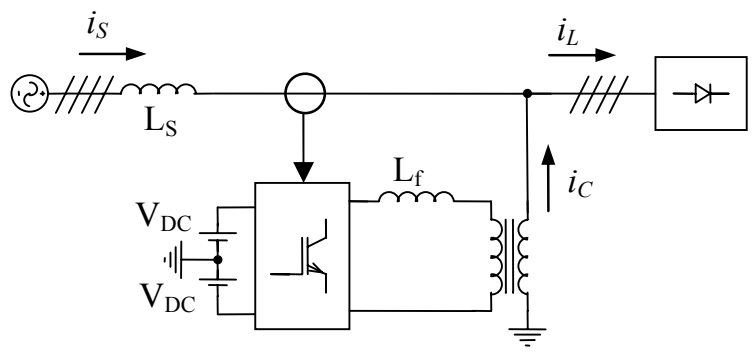

Fig. 1. Parallel Active Filter, PAF.

To eliminate the load harmonics, the PAF control loop determines the converter reference current. Thus, for each harmonic of $\mathrm{h}$ order different from fundamental, it is:

$$
I_{C h}=I_{L h}-I_{S h}=I_{L h} \quad ; \quad \forall h
$$

where $I_{L h}$ is the load current harmonic to mitigate. According to (1), after shunt compensation, the source current is:

$$
i_{S}=i_{L 1}
$$

That is, the source current is identified with the load current fundamental component, and therefore its waveform is sinusoidal.

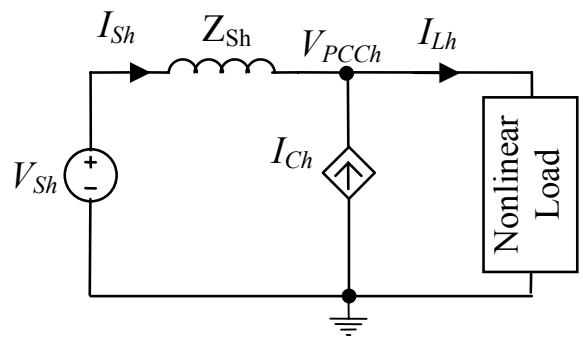

Fig. 2. Equivalent single phase circuit of a PAF

For loads of type HCS, the PAF filtering characteristics are not influenced by the source impedance $Z_{S}$. Nevertheless, for loads of type HVS, the load current depends on $Z_{S}$, PAF has difficulties to generate the compensation harmonics. In this case, harmonic current injected by the PAF will flow into the load and PAF is not be able to mitigate the harmonics on supply side, [1-3].

\section{B. Series active filter, $S A F$}

Fig. 3 shows the SAF connection to a power system. In this case, the compensation strategy consists of the generation of a voltage proportional to the source current harmonics. Thus, $V_{C h}=k I_{S h}$, where h is the order of each harmonic, [6].

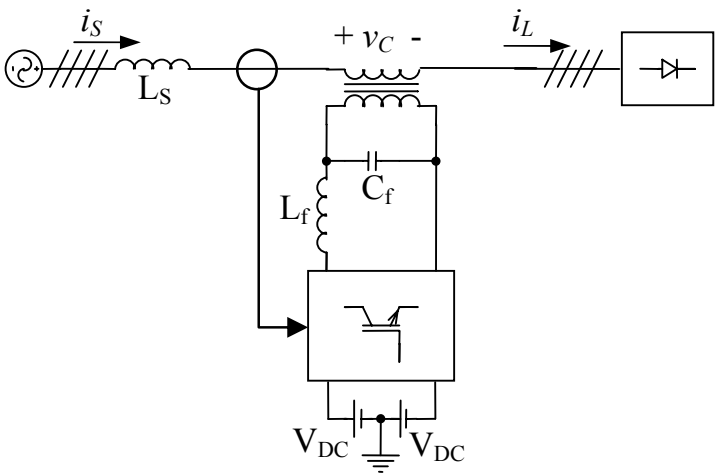

Fig. 3. Series Active Filter, SAF

In Fig. 4, the equivalent single-phase circuit is shown, corresponding to $\mathrm{h}$ harmonic order, for $\mathrm{h}>1 . Z_{S h}$ represents the source impedance at $h$ harmonic frequency. Considering $h>1$, the source current is calculated by the next expression:

$$
I_{S h}=\frac{V_{S h}}{\left(Z_{S h}+k\right)}-\frac{V_{L h}}{\left(Z_{S h}+k\right)}
$$

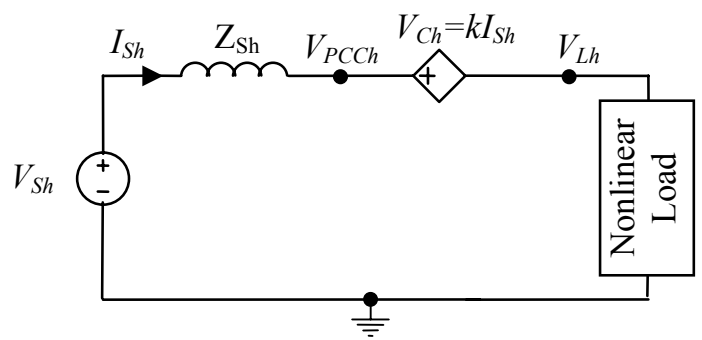

Fig. 4. Equivalent single phase circuit of a series active filter, SAF 
With respect to parameter $k$, a value $k>>Z_{s}$ allows the source current harmonics to be mitigated.

$$
I_{S h} \approx 0 ; k>>Z_{S}
$$

On the other hand, the harmonic voltage at PCC includes two terms, the first one is related to harmonics background of supply voltage and the second one is related to load voltage harmonics.

$$
V_{P C C h}=\frac{k}{\left(Z_{S h}+k\right)} V_{S h}-\frac{Z_{S h}}{\left(Z_{S h}+k\right)} V_{L h}
$$

With respect to parameter $k$, a value $k>>Z_{s}$ reduces voltage harmonics at PCC produced by load voltage harmonics.

However, the analysis of equations (3)-(5) is worth for loads of type HVS. For loads HCS, SAF cannot achieve the harmonic compensation, [1].

\section{Parallel passive-active filter, $P P A F$}

Fig. 5 shows the PPAF connection to a power system. In this configuration, the active filter generates a voltage proportional to the source current harmonics in the same way as in SAF topology.

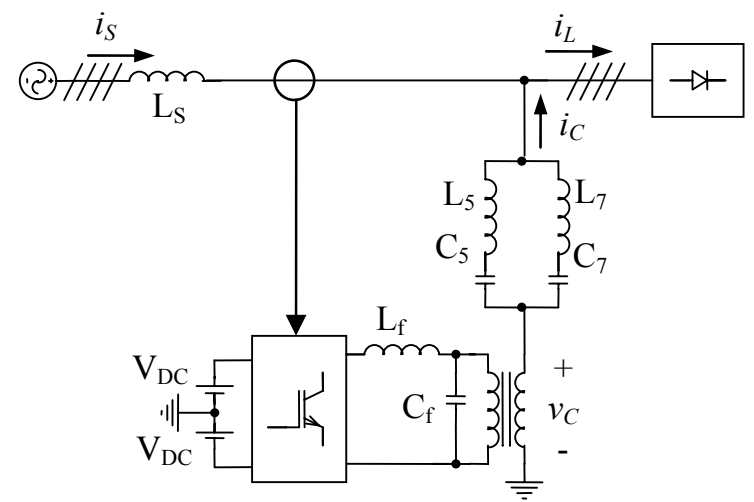

Fig. 5. Parallel Passive-Active Filter, PPAF

In Fig. 6, the equivalent single-phase circuit corresponding to a harmonic $\mathrm{h}$ is shown. According to this circuit, source current can be calculated as follows:

$$
I_{S h}=\frac{Z_{F h}}{\left(Z_{S h}+Z_{F h}+k\right)} I_{L h}+\frac{1}{\left(Z_{S h}+Z_{F h}+k\right)} V_{S h}
$$

With respect to the parameter $\mathrm{k}$, a value $\mathrm{k}>>\mathrm{Z}_{\mathrm{S}}$ and $\mathrm{k}>>\mathrm{Z}_{\mathrm{F}}$ allows the source current harmonics to be mitigated, improving LC passive filter characteristics. Thus,

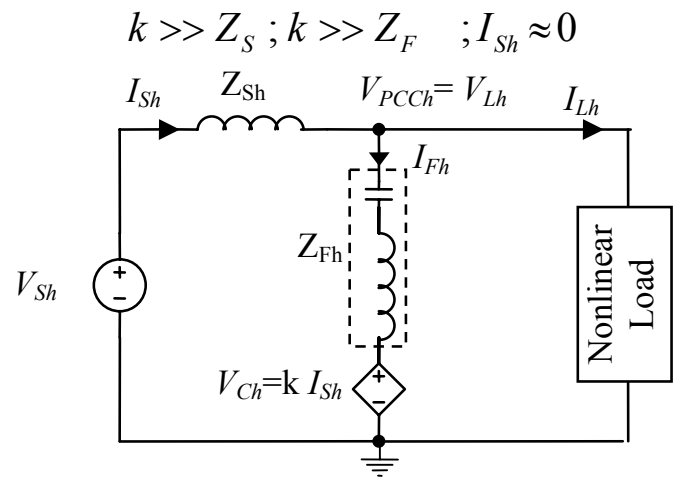

Fig. 6. Equivalent single phase circuit of a PPAF

\section{Series active and parallel passive filter, SAPPF}

Fig. 7 shows the SAPPF connection to a power system. In this configuration, the active filter generates a voltage proportional to the source current harmonics, in the same way as in two previous configurations.

In Fig. 8, the equivalent single-phase circuit corresponding to a harmonic $h$ is shown. The source harmonic current can be calculated by mean of the expression:

$$
I_{S h}=\frac{Z_{F h}}{\left(Z_{S h}+Z_{F h}+k\right)} I_{L h}+\frac{1}{\left(Z_{S h}+Z_{F h}+k\right)} V_{S h}
$$

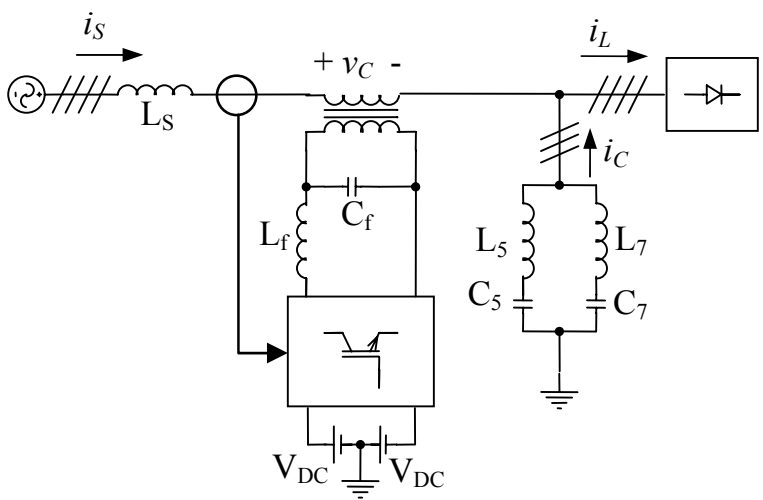

Fig. 7. Series Active and Parallel Passive Filter, SAPPF

Equation (8), is the same as equation (6), corresponding to PPAF configuration. Nevertheless, SAPPF configuration includes a series active filter that achieves a voltage in PCC which can be calculated, according to Fig. 8, as follows:

$$
V_{P C C h}=\frac{k}{\left(Z_{S h}+k\right)} V_{S h}+\frac{Z_{S h}}{\left(Z_{S h}+k\right)} V_{L h}
$$

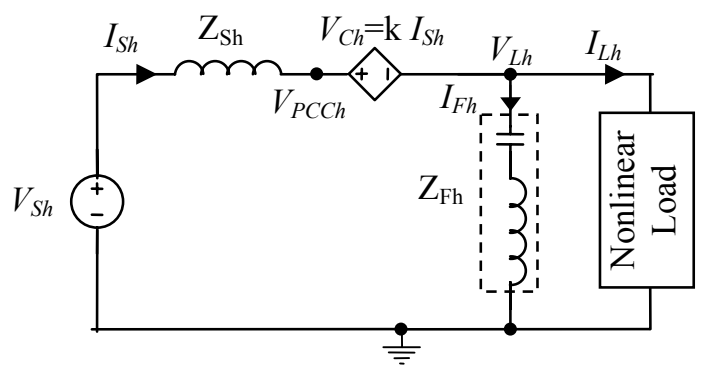

Fig. 8. Equivalent single phase circuit of a SAPPF

Therefore, if parameter $\mathrm{k}$ has a value $\mathrm{k}>>\mathrm{Z}_{\mathrm{S}}$, SAPPF topology insulates PCC load voltage harmonics, [10-12].

\section{Experimental Power System}

An experimental prototype to test each APF topology has been developed. With respect to the active filter control and according to previous section, all the strategies need the current harmonics as reference. To calculate it, the scheme shown in Fig. 9 has been used, [13,14]. The measured source current is multiplied by $\sin \omega t$ and $\cos \omega t$ where $\omega$ is the fundamental frequency in $\mathrm{rad} / \mathrm{s}$. The average values of the results are obtained using two low pass filters. They are multiplied by $\sin \omega t$ and $\cos \omega t$ again 
and then by 2 . This allows the current fundamental component to be obtained.

Each compensation strategies corresponding to the four analyzed topologies were implemented in data acquisition and control card. It is compatible with MATLABSimulink ${ }^{\circledR}$ and it has been developed by dSPACE. The control board has a PowerPC 750GX processor running at $1 \mathrm{GHz}$. this board. The sampling rate was limited to $50 \mu \mathrm{s}$ in order to avoid overrun errors.

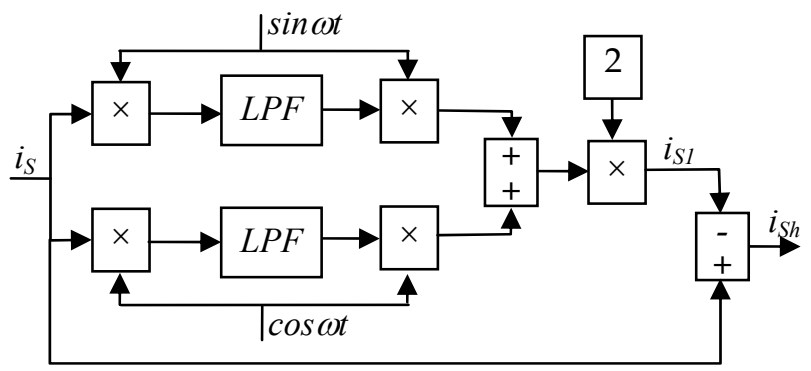

Fig. 9. Block diagram to determinate current harmonics

A hysteresis band control was developed. The converter IGBT (Insulated Gate Bipolar Transistor) gating signals are generated comparing the reference signal with the inverter output voltage considering a hysteresis band. In this control type, switching frequency is variable, although in our design this frequency is limited to $20 \mathrm{kHz}$ to not reach the IGBTs maximum switching frequency.

Active filter is a three-leg, VSI converter. Here, a Semikron SKM50GB123-type IGBT bridge has been used. It has two $2200 \mu \mathrm{F}$ capacitors in series on DC bus, with the midpoint accessible to connect the neutral wire. Active filter output includes a small passive filter to eliminate the ripple of the output waveform due to high frequencies switching. PAF configuration, with a control by current, has a $13.5 \mathrm{mH}$ inductance, (Fig. 1). The remaining topologies, series and hybrid, include a set of LC values $\mathrm{L}_{\mathrm{f}}=13.5 \mathrm{mH}$ and $\mathrm{C}_{\mathrm{f}}=50 \mu \mathrm{F}$, respectively, Fig. 3, 5 and 7.

Harmonic compensation tests were carried out in the power system shown in Fig. 10. The system allows two different nonlinear loads to be combined. The first one is an uncontrolled three-phase rectifier with a $2200 \mu \mathrm{F}$ capacitor in parallel to a $50 \Omega$ resistor on DC side. The second one is a three-phase ac regulator. Each branch is constituted by two antiparalell SCRs in series to a $16 \Omega$ resistor and a $27.5 \mathrm{mH}$ inductance. Each set of SCRs presents the same firing angle. By means of two switches $\mathrm{K} 1$ and $\mathrm{K} 2$, the connection of only one three-phase load or both together is possible, according to interests.

The set of loads is conected to a $4500 \mathrm{iL}$ programmable source from California Instruments, which generates a balanced sinusoidal three phase voltage at $50 \mathrm{~Hz}$. Additional source impedance, constituted by a $1.8 \Omega$ resistor in series to a $2.8 \mathrm{mH}$ inductance, has been included.

Finally, among the four compensation devices analyzed in this work, two of them include LC passive filters. In these configurations two sets of LC branches tuned to $5^{\text {th }}$ and $7^{\text {th }}$ harmonics have been disposed. Table I shows $\mathrm{L}$ an $\mathrm{C}$ values.

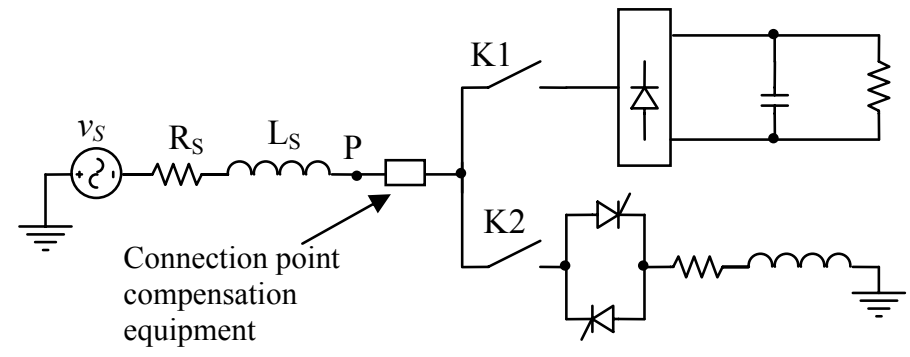

Fig. 10. Experimental power system

Table I. Passive filter values

\begin{tabular}{|l|l|l|}
\hline $5^{\text {th }}$ harmonic & $\mathrm{L}_{5}=13.5 \mathrm{mH}$ & $\mathrm{C}_{5}=30 \mu \mathrm{F}$ \\
\hline $7^{\text {th }}$ harmonic & $\mathrm{L}_{7}=6.75 \mathrm{mH}$ & $\mathrm{C}_{7}=30 \mu \mathrm{F}$ \\
\hline
\end{tabular}

\section{Practical Results}

In this section, voltage and current waveforms and THD values in PCC are presented. The four configurations of harmonic compensation are considered. Three cases have been analyzed according to the switch states of the Fig. 10 .

\section{A. Case 1: K1 on, K2 off.}

As first case, results corresponding to the power system shown in Fig. 10 before and after compensation are presented, when the load connected is the three-phase rectifier with a capacitive load on DC side. Fig. 11 a) presents the voltage waveform in PCC and the supply current corresponding to the phase "a" obtained from a LECROY Wavesurfer 424 oscilloscope. Figures 11 b), c), d) and e) present the voltage and current waveforms, when each harmonic compensation equipment is connected.

A preliminary analysis of the waveforms shows that those configurations which include a series active filter achieve the improvement of voltage and current distortion. SAPPF topology aims waveforms practically sinusoidal. SAF topology aims the mitigation of the distortion in a considerable level, while the rest of configurations do not achieve to significantly reduce distortion.

A rectifier with smoothing DC capacitor is a HVS nonlinear load. Thus, line current harmonics amplitude strongly depends on the source impedance, while voltage in its terminals practically does not depend on the ac impedance. With respect to this type of load, shunt connection configurations, PAF and PPAF are not effective from the point of view of harmonic compensation.

Table II includes voltage and current THD and RMS values measured with the EPQ Fluke 434 analyzer.

Table II.- Measurement values with a rectifier

\begin{tabular}{|c|c|c|c|c|c|c|c|c|c|c|}
\multicolumn{1}{c|}{} & \multicolumn{2}{c|}{ BC } & \multicolumn{2}{c|}{ SAF } & \multicolumn{2}{c|}{ PAF } & \multicolumn{2}{c|}{ PPAF } & \multicolumn{2}{c|}{ SAPPF } \\
\cline { 2 - 11 } \multicolumn{1}{c|}{} & $\mathrm{V}$ & $\mathrm{I}$ & $\mathrm{V}$ & $\mathrm{I}$ & $\mathrm{V}$ & $\mathrm{I}$ & $\mathrm{V}$ & $\mathrm{I}$ & $\mathrm{V}$ & $\mathrm{I}$ \\
\hline THD (\%) & 9.4 & 35.1 & 1.9 & 7.5 & 10.0 & 30.5 & 7.6 & 26.1 & 0.9 & 2.3 \\
\hline RMS (V,A) & 103.7 & 4.1 & 99.4 & 3.3 & 98.4 & 4.3 & 100.6 & 4.2 & 100.5 & 3.9 \\
\hline
\end{tabular}




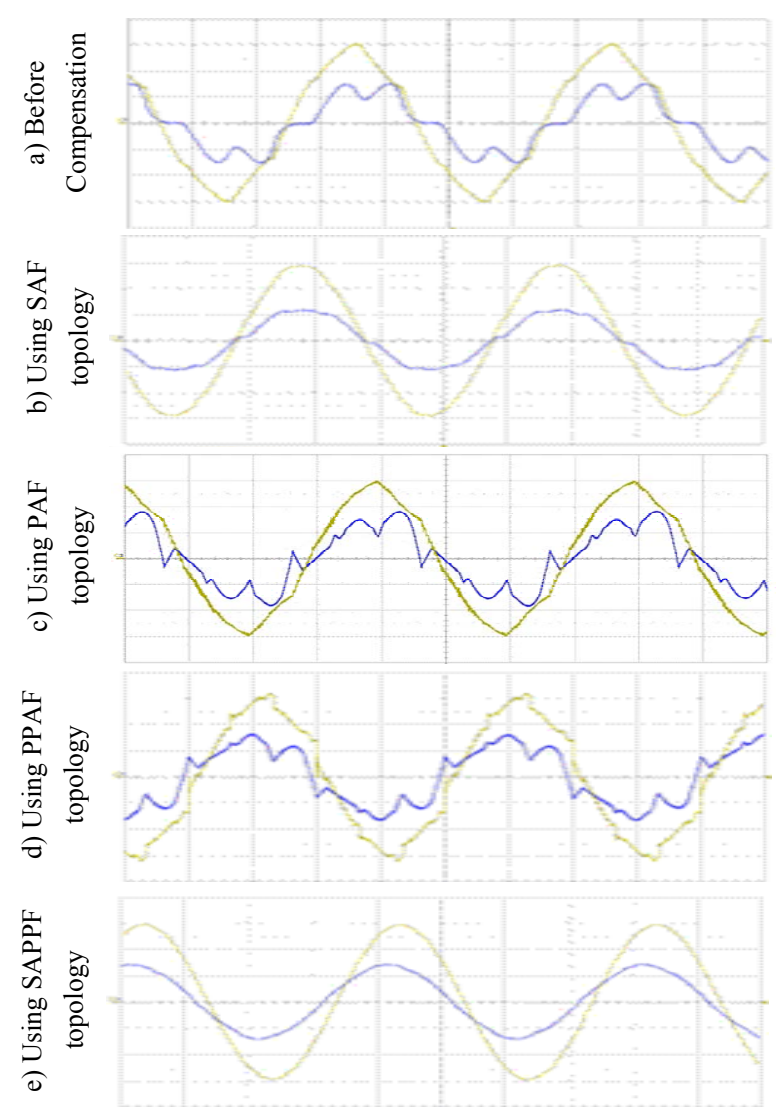

Fig. 11. Phase-a PCC voltage (50 V/div) and source current (3.9 A/div) waveforms with a rectifier

\section{B. Case 2: $K 1$ off, $K 2$ on.}

In this case the power system is only constituted by the load composed of a three-phase regulator. This is a HCS type load because of source impedance has little effect on the current harmonics.

Fig. 12 a) shows voltage and current waveforms before compensation. Fig. 12 b), c), d) and e) present voltage and current waveforms after compensation using each topology. In this case three of four configurations aim an important reduction in voltage and current distortion. The three topologies that include components in parallel to the load achieve to mitigate the current harmonics produced by a CHS type load. Only SAF configuration does not allow current harmonics cancelation, because of series compensator topology and load harmonic character.

Table III presents the results of THD and RMS values measured before and after compensation. Numerical results confirm the preliminary analysis obtained looking at system waveforms, Fig. 12.

Table III.- Measurement values with a regulator

\begin{tabular}{|l|c|c|c|c|c|c|c|c|c|c|}
\cline { 2 - 11 } \multicolumn{1}{c|}{} & \multicolumn{2}{c|}{ BC } & \multicolumn{2}{c|}{ SAF } & \multicolumn{2}{c|}{ PAF } & \multicolumn{2}{c|}{ PPAF } & \multicolumn{2}{c|}{ SAPPF } \\
\cline { 2 - 11 } \multicolumn{1}{c|}{} & $\mathrm{V}$ & $\mathrm{I}$ & $\mathrm{V}$ & $\mathrm{I}$ & $\mathrm{V}$ & $\mathrm{I}$ & $\mathrm{V}$ & $\mathrm{I}$ & $\mathrm{V}$ & $\mathrm{I}$ \\
\hline THD (\%) & 4.2 & 27.9 & 3.0 & 19.0 & 1.5 & 5.1 & 0.8 & 3.9 & 0.8 & 4.9 \\
\hline RMS (V,A) & 96.3 & 3.3 & 97.9 & 2.6 & 97.0 & 3.4 & 99.3 & 2.4 & 99.1 & 2.4 \\
\hline
\end{tabular}

\section{Case 3: K1 on, K2 on.}

Case 1 and 2 present the experimental results corresponding to two types of non-linear loads whose harmonic characteristics are dual. The first one is voltage harmonic source and the second one current harmonic source. In this case both loads have been simultaneously connected, and the load presents an intermediate behavior. Thus, with $\mathrm{K} 1$ on and $\mathrm{K} 2$ on, the load is composed of a $1.18 \mathrm{kVA}$ three-phase rectifier and a $0.98 \mathrm{kVA}$ threephase regulator.

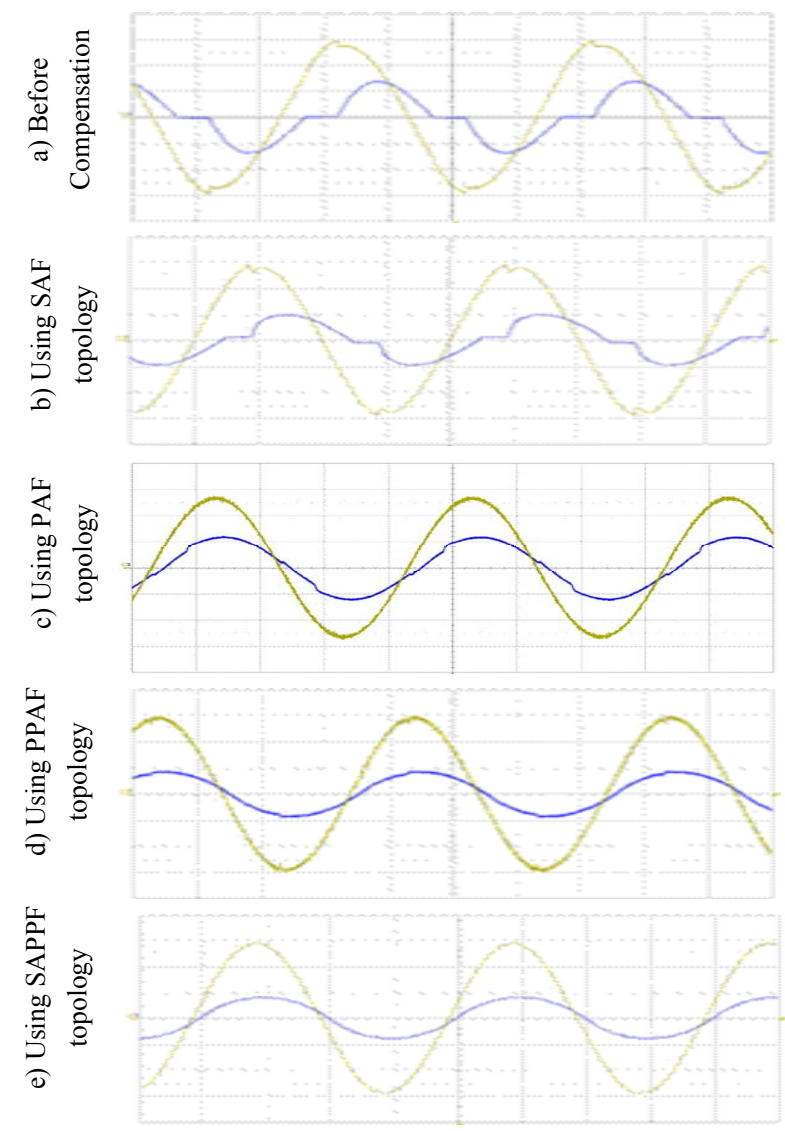

Fig. 12. Phase-a voltage $(50 \mathrm{~V} / \mathrm{div})$ and current $(3,9 \mathrm{~A} / \mathrm{div})$ waveforms with a regulator

Fig. 13 shows voltage and current waveforms before and after compensation for each APF topology. In this case, only the configurations with series APF aim the reduction of distortion in a meaningful way. Table IV presents the measures THD and RMS values. It can be noticed as SAF configuration achieves the decreasing of current THD from $19.2 \%$ to $5.8 \%$. The SAPPF decreases the same parameter to a value of $2 \%$. The rest of configurations hardly aim to decrease THD values.

Table IV.- Measurement values with a rectifier + regulator

\begin{tabular}{|l|c|c|c|c|c|c|c|c|c|c|}
\multicolumn{1}{c|}{} & \multicolumn{2}{|c|}{ BC } & \multicolumn{2}{c|}{ SAF } & \multicolumn{2}{c|}{ PAF } & \multicolumn{2}{c|}{ PPAF } & \multicolumn{2}{c|}{ SAPPF } \\
\cline { 2 - 10 } \multicolumn{1}{c|}{} & V & I & V & I & V & I & V & I & V & I \\
\hline THD (\%) & 8.0 & 19.2 & 2.0 & 5.8 & 9.4 & 17 & 7.6 & 16.6 & 1.1 & 2.0 \\
\hline RMS (V,A) & 93.6 & 6.8 & 96.7 & 5.5 & 95.1 & 7.2 & 97.5 & 6.3 & 98.0 & 5.7 \\
\hline
\end{tabular}




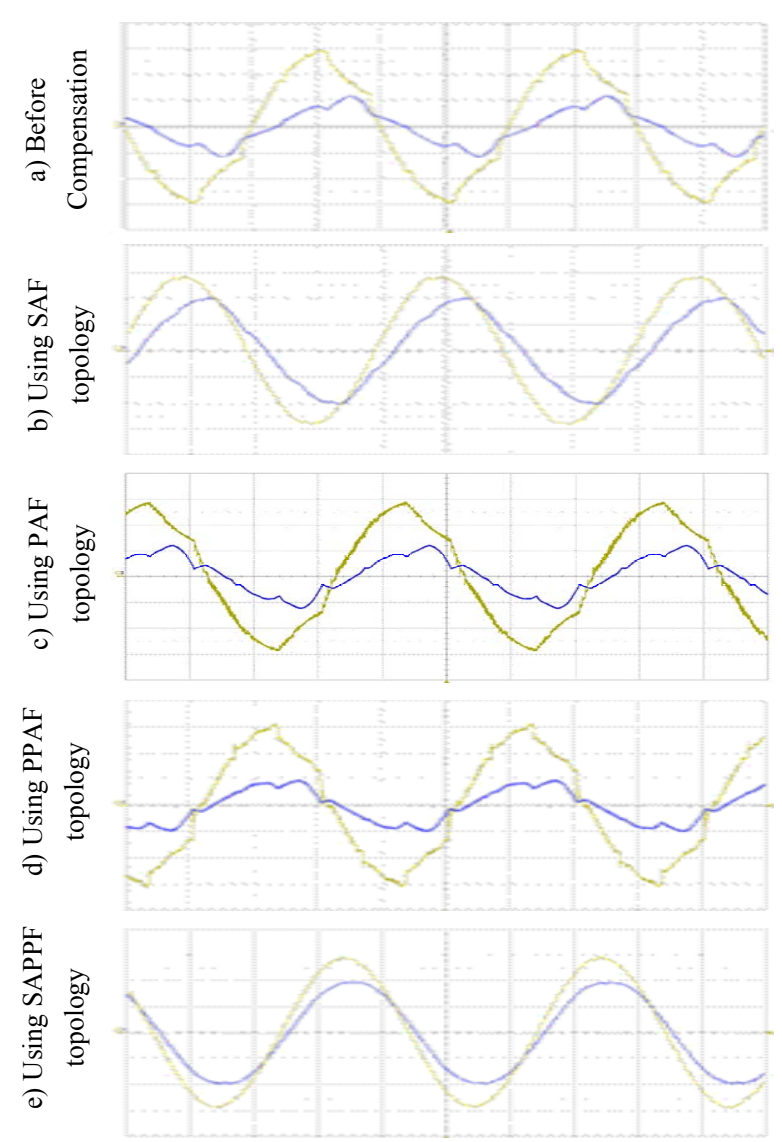

Fig. 13. Phase a voltage $(50 \mathrm{~V} / \mathrm{div})$ and current $(3,9 \mathrm{~A} / \mathrm{div})$ waveforms with a rectifier + regulator load

\section{Conclusion}

Four different active filter topologies to eliminate harmonics have been analyzed. They are series active filter SAF, parallel active filter PAF, parallel passiveactive filter PPAF and series active and parallel passive filter SAPPF.

A test bank has been designed composed of a harmonic voltage source (HVS) load and another harmonic current source (HCS) load, with the possibility of individual or joint connection. It allows the availability of non-linear loads with different harmonic production. Thus, an experimental analysis has been carried out about three different cases corresponding to the connection of a threephase rectifier with smoothing DC capacitor, a threephase regulator or a set constituted by both loads.

In each case, voltage and current waveforms were recorded and measures were made before and after harmonic compensation using each configuration. In all compensation equipments, the active filter control was designed to mitigate load harmonics.

The analysis of experimental results has allowed next conclusions to be obtained:

- VHS loads require active compensator which includes a series active power filter (SAF, SAPPF). In this case, the hybrid configuration presents better results than only series active filter.

- CHS loads require configurations which include elements parallel to load (PAF, PPAF, SAPPF). In this situation, hybrid configurations present better results than shunt active filter.
- Loads with an intermediate behavior where the percentage of HVS load is the greatest require configurations with series active filter (SAF, SAPPF)

Finally, the global analysis of results has reveled that SAPPF configuration is compensation equipment versatile which allows harmonics to be mitigated with any type of load. This configuration obtains better results than the rest of topologies in all situations.

\section{References}

[1] F. Z. Peng, "Harmonics sources and filtering approaches," in Proc. Industry Aplications Conference, October 1999, Vol, 1, pp. 448-455

[2] H. Akagi, "Active harmonic filters," Proceedings of the IEEE, Vol. 93, Issue 12, Dec. 2005, pp. 2128-2141

[3] Singh, B.; Al-Haddad, K.; Chandra, A. "A review of active filters for power quality improvement" IEEE Trans. on Industrial Electronics, Vol. 46, Issue 5, Oct. 1999, pp. 960 $-971$

[4] Orts, S.; Gimeno-Sales, F.J.; Abellan, A.; Segui-Chilet, S.; Alcaniz, M.; Masot, R, "Achieving Maximum Efficiency in Three-Phase Systems With a Shunt Active Power Compensator Based on IEEE Std. 1459", IEEE Trans. on Power Delivery, Vol. 23, Issue 2, April 2008, pp. 812 822

[5] Corasaniti, V. F.; Barbieri, M. B.; Arnera, P. L.; Valla, M. I., "Hybrid Active Filter for Reactive and Harmonics Compensation in a Distribution Network ", IEEE Trans. on Industrial Electronics, Vol. 56, Issue 3, March 2009, pp. 670-677

[6] Z. Wang, Q. Wang, W. Yao and J. Liu, "A series active power filter adopting hybrid control approach," IEEE Trans. Power Electronics, Vol. 16, No. 3, May 2001, pp. 301-310

[7] Zeliang Shu; Yuhua Guo; Jisan Lian, "Steady-State and Dynamic Study of Active Power Filter With Efficient FPGA-Based Control Algorithm", IEEE Trans. on Industrial Electronics, Vol. 55, Issue 4, April 2008, pp. 1527-1536

[8] H. Fujita, H. Akagi, "A practical approach to harmonic compensation in power systems: series connection of passive and active filters", IEEE / IAS Ann. Conf. Rec., pp. 1107 - 1112, 1990.

[9] An Luo; Zhikang Shuai; Wenji Zhu; Ruixiang Fan; Chunming Tu. "Development of hybrid active power filter based on the adaptive fuzzy dividing frequency-control method," IEEE Trans on Power Delivery, Vol. 24, Issue 1, Jan. 2009, pp. 424-432

[10] F. Z. Peng, H. Akagi, A. Nabae, "A new approach to harmonic compensation in power systems a combined system of shunt passive and series active filters," IEEE Trans. Industry Applications. Vol, 26, No. 6, Nov/Dec 1990, pp. 983-990

[11] Y. S. Kim, J. S. Kim and S. H. Ko, "Three-phase three-wire series active power filter, which compensates for harmonics and reactive power", IEE proc. Electric. Power Applications, Vol, 151, No. 3, May 2004, pp. 276-282.

[12] Salmerón, P. Litrán, S.P., "A Control Strategy for Hybrid Power Filter to Compensate Four-Wires Three-Phase Systems", IEEE Trans. on Power Electronics, Vol. 25, Isue 7, 2010, pp. 1923-1931

[13] Herrera, R. S.; Salmerón, P.; Kim, H.; "Instantaneous Reactive Power Theory Applied to Active Power Filter Compensation: Different Approaches, Assessment, and Experimental Results", IEEE Trans. on Industrial Electronics, Vol. 55, Issue 1, Jan. 2008, pp. 184-196 